\title{
ОСОБЕННОСТИ ЭМОЦИОНАЛЬНОЙ СФЕРЫ ПОДРОСТКОВ, ПОДВЕРГШИХСЯ ФИЗИЧЕСКОМУ НАСИЛИЮ В СЕМЬЕ
}

\author{
Разина Н.В. (РГГУ, Москва, Россия) \\ natraz@inbox.ru
}

Даньшина Д.С. (Школа № 2103,Москва, Россия)

danshina.darya@yandex.ru

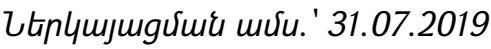

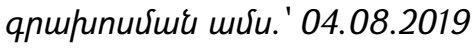

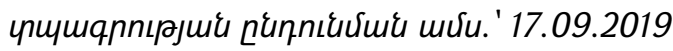

В статье представлены результаты сравнительного анализа

\begin{abstract}
выраженности симптомов посттравматического расстройства между
\end{abstract} подростками, которые подвергались фризическому насилию в семье, и теми, кто не испытывал насилия внутри семьи. Не смотря на отсутствие значимых различий в выраженности симптомов посттравматического расстройства, были обнаружены различия в корреляционных связях между рядом параметров эмоциональной сферы детей, подвергшимся и не подвергшимся фризическому насилию в семье. Также было обнаружено, что подросткам, подвергшимся фризическому насилию в семье, в большей мере, свойственно чувство, вызванное завистью и ненавистью к окружающим, обусловленное горечью, гневом на весь мир за действительные или мнимые страдания.

Ключевые слова: эмочиональная сфера, насилие, посттравматическое стрессовое расстройство, агрессия, личностная тревожность.

Семья оказывает колоссальное влияние на формирование личности подростка, его модель взаимодействия с миром, жизненные ценности и интересы. Эмоциональные отношения в семье играют важную объединяющую роль, благодаря которой члены благополучной семьи ощущают себя единым целым и чувствуют теплоту и поддержку друг друга. Однако именно в родительской семье зачастую ребенок впервые сталкивается с конфликтами, негативными эмоциями и физическими наказаниями.

Домашнее насилие над детьми является одной из злободневных проблем современного общества. На сегодняшний момент тема абъюза (с англ. «abuse» злоупотребление, оскорбление, плохое обращение) получила широкое распространение в СМИ и профессиональном сообществе в России в связи с вступлением в силу закона о декриминализации домашнего насилия. Увеличение числа детей, подвергшихся семейному насилию, сложности в выявлении его мотивов и признаков, а также важность последствий насилия для развития личности ребенка постоянно требуют внимания исследователей. По вышеуказанным причинам большой научный и практический интерес представляет психологическое 
исследование особенностей эмоциональной сферы детей, подвергшихся насилию, в частности, физическому насилию в семье.

Проблема насилия стала предметом пристального изучения и в целом ряде отечественных работ (Е.А. Бабаева, О.В. Дворецкая, Л.М. Курзин, И. А. Алексеева, И. Г. Новосельский, Е. Н. Волкова, А. Ю. Егоров, О. Г. Фрейдман, Т. М. Журавлёва, Т. Я. Сафонова, И. А. Фурманов, Е. И. Цымбал и др.). Так, в исследованиях М. Брюкнер [2, 261], Е.А. Бабаевой [1,171], О.В. Дворецкой [3,1], Л.М. Курзина [4,753] насилие и жестокое обращение с детьми рассматривается как одна из возможных причин нездорового развития ребенка и антиобщественного детства, а так же последствия насилия вызывают тяжелые психологические травмы и оказывают отрицательное влияние на личность ребенка. Среди выделяемых форм жестокого обращения с детьми в семье наибольший интерес в последнее время представляет физическое насилие в силу его широкой распространенности.

Домашнее физическое насилие определяется как намеренное нанесение физического вреда ребёнку родителями или опекунами, ответственными за их воспитание.

Основываясь на работах отечественных и зарубежных исследователей (Е.Е. Лупанова, Г.Р. Гильманшина, И.А. Фурманов, М.Брюкнер, Г. Паренс), можно сделать вывод о том, что жестокое обращение по отношению к детям оказывает влияние на их эмоциональную сферу, так как в подавляющем большинстве случаев несет за собой значительную физическую и душевную травму. Н. В. Тарабрина, Е. Д. Соколова, Е. О. Лазебная, М. Е. Зеленова, И. Г. Малкина-Пых рассматривают переживание насилия, как посттравматическое стрессовое расстройство (далее ПТСР). Это состояние сопровождается убежденностью в собственной неполноценности, постоянном ощущении себя «хуже всех». Вследствие этого ребенку трудно добиться уважения окружающих, успеха, общение его со сверстниками затруднено [5,79].

Физическое насилие в семье может оказывать сильное отрицательное влияние на формирование эмоциональной сферы ребенка. Основными эмоциональными реакциями на абъюз могут быть чувство ответственности за насилие; чувство вины; постоянное возбуждение; переживание потери; противоречивость; страх быть покинутым; потребность в чрезмерном внимании взрослых; боязнь телесных повреждений; стыд; беспокойство о будущем. Подростки, пострадавший от домашнего физического насилия, часто испытывают гнев, который обращают на младших детей и животных. Ненормальная обстановка способствует формированию у ребёнка низкой самооценки, поэтому он сам начинает относиться к себе с презрением и недоброжелательностью. У детей, подвергшихся физическому насилию в семье, могут наблюдаться отчетливые или запрятанные садистские наклонности: издевательства над животными, над более слабыми детьми. Трудность проблемы домашнего насилия над детьми говорит о необходимости комплексного плана действий, главными целями которого являются 
предотвращение семейного насилия, защита ребенка от него, а также обеспечение профессиональной помощью.

В результате анализа имеющихся исследований в данной области можно предположить, что существуют различия в эмоциональном состоянии детей в зависимости от присутствия в их жизни фрактов физического насилия в семье.

В данном исследовании проверялся ряд частных гипотез: подростки, подвергавшиеся фризическому насилию в семье, имеют более высокий уровень посттравматического стресса; подросткам, пережившим такие травмирующие события как фризическое насилие в семье, свойственна повышенная агрессивность с такими специфическими проявлениями как склонность к фризической агрессии, обидчивости и подозрительности; психическая травма, полученная ребенком в результате физического насилия в семье, приводит к изменению уровня его тревожности.

Для проверки выдвинутых гипотез и решения поставленных задач было проведено исследование взаимосвязи перенесенной психической травмы в результате насилия и уровней посттравматического стресса, агрессивности и тревожности. Были опрошены две группы респондентов, всего в исследовании приняли участие 44 подростка в возрасте от 13 до 16 лет. Группу-1 составили 23 подростка, не подвергавшихся фризическому насилию в семье. Группа-2 включала в себя 21 подростка, подвергавшихся фииическому насилию в семье.

Для изучения состояния эмоциональной сферы респондентов были использованы следующие методики:

$>$ Полуструктурированное интервью для оценки травматических переживаний детей (разработано Н.В. Тарабриной).

$>$ Методика «Шкала личностной тревожности учащихся 10-16 лет» (автор А.М. Прихожан).

$>$ «Опросник агрессивности Басса-Дарки (англ. Buss - Durkee Hostility Inventory, сокр. BDHI)».

Были получены неоднозначные результаты выраженности симптомов посттравматического стрессового расстройства у детей, не подвергавшихся насилию и подвергшихся физическому насилию в семье.

Количественный анализ данных симптомов ПТСР в исследовательских группах (не подвергавшихся насилию Группа-1 и подвергшихся фризическому насилию в семье Группа-2) показал, что в Группе-2 симптомы по всем критериям выражены в большей степени. Данные свидетельствуют о том, что показатели шкал, соответствующих критериям «В» «Навязчивое воспроизведение», «С» (Избегание), «D» (Возросшая возбудимость) и «F» (Нарушения функционирования) с точки зрения подростков, не подвергавшихся и подвергшихся фризическому насилию в семье, не одинаковы. Так, показатели по шкалам «B», « $\mathrm{C}$, « $\mathrm{D}$ » и « $F$ » выше в Группе-2. У респондентов, подвергшихся фризическому насилию в семье, 
показатели критерия «С» (Избегание) значительно выше остальных: среднегрупповое значение - 10,9 балла. А у не подвергавшихся насилию, показатели критерия «В» (Навязчивое воспроизведение) значительно выше остальных: среднегрупповое значение - 9,7 балла.

Таким образом, посттравматическое стрессовое расстройство у подростков Группы-2 наиболее затрагивает изменения в реакциях на пережитую ситуацию (критерий «A»), а в наименьшей степени - изменения поведения (критерий «F»). То есть испытуемые, которые подверглись физическому насилию в семье, в большей степени, чем испытуемые, которые не подвергались насилию, начинают избегать мыслей, разговоров, ситуаций и действий, мест и людей, напоминающих о травматических переживаниях или ситуациях, связанных с травмой; скрывать и не показывать реакции, связанные с травмой; часто они не в состоянии вспомнить важные аспекты травмы.

Также был проведен статистический анализ данных на значимость различий между группами по выраженности симптомов ПТСР. Ни один из рассматриваемых критериев травматических переживаний детей, не подвергавшихся насилию и подвергшихся фризическому насилию в семье, не находится в зоне статистической значимости.

Таким образом, в результате проведенного исследования предположение о том, что дети, подвергавшиеся ффизическому насилию в семье, имеют более высокий уровень посттравматического стресса, не подтвердилось.

На наш взгляд, отсутствие статистической значимости различий в уровнях посттравматического стрессового расстройства между группами испытуемых можно объяснить их вступлением в раннее половое созревание и началом специфических подростковых психических перемен, непосредственно связанных с приспособлением к обществу. В раннем подростковом возрасте становится намного сложнее ощутить поддержку родителей, потому что появляются особенности в отношениях между родителями и детьми в связи с возникновением семейных конфликтов, связанных с самоопределением ребенка. Возможно, душевный мир и ценностные ориентации испытуемых подростков начинают меняться и такие изменения могли вызвать у них состояние беспокойства, что, в свою очередь, способствует ухудшению его психического состояния. Если в этот период происходят какие-либо травматические события - физическое насилие в семье, например, интенсивность переживаний таких событий у испытуемых может увеличиться. Предполагаем, что именно этот эффект и наблюдается в полученных результатах.

Не смотря на опровержение гипотезы, о более высоком уровне выраженности ПТСР у Группы-2, в исследовательских группах были выявлены разные взаимосвязи между критериями травматических переживаний подростков.

По результатам проведенного анализа у подростков, подвергшихся фризическому насилию, отмечено наличие статистически значимых связей между 
критерием «A» (Немедленное реагирование) и критерием «В» (Навязчивое воспроизведение) ( $r$-Спирмена $=0,762$ при $p \leq 0,01)$; критерием «A» (Немедленное реагирование) и критерием «D» (Возросшая возбудимость) $(r$ - Спирмена $=0,762$ при $\mathrm{p} \leq 0,01)$; критерием «A» (немедленное реагирование) и критерием «F» (Нарушения фрункционирования) ( $r$-Спирмена $=0,810$ при $\mathrm{p} \leq 0,05)$; критерием «C» (Избегание) и критерием «D» (Возросшая возбудимость) (r-Спирмена = 0,827 при $\mathrm{p} \leq 0,01)$; критерием "C» (Избегание) и критерием «F» (Нарушения фрункционирования) (r-Спирмена $=0,757$ при $\mathrm{p} \leq 0,01)$; критерием «D» (Возросшая возбудимость) и критерием «F» (Нарушения функционирования) ( $r$-Спирмена = 0,941 при p $\leq 0,01$ ).

Таким образом, чем более навязчиво подросток, подвергавшийся фризическому насилию в семье, прокручивает в своей памяти травматические события, образы, вызывающее тяжелые эмоциональные переживания, тем чаще у него повторяются плохие сны и кошмары.

В группе подростков, не подвергавшихся насилию, имеет место другая картина взаимосвязей между клиническими и социально-психологическими проявлениями посттравматического стрессового расстройства; отмечено наличие статистически значимых связей между критерием «B» (избегание) и критерием «D» (возросшая возбудимость) ( $r$-Спирмена $=0,578$ при $p \leq 0,01)$; критерием «D» (возросшая возбудимость) и критерием «F» (нарушения функционирования) (rСпирмена = 0,613 при $\mathrm{p} \leq 0,01)$; критерием “C» (избегание) и критерием «B» (Навязчивое воспроизведение) ( $r$-Спирмена $=0,751$ при $\mathrm{p} \leq 0,01)$.

Следует отметить, что, результаты данного эмпирического исследования продемонстрировали наличие в обеих подгруппах подростков сильной прямой корреляционной связи между уровнем возбудимости и функционированием. Другими словами, повышенный уровень настороженности, гипербдительность, состояние постоянного ожидания угрозы вызывает у респондентов, независимо от того, подвергались они физическому насилию в семье, или не подвергались насилию вовсе, тяжелое эмоциональное состояние или нарушения в социальной или других важных сорерах жизнедеятельности.

Полученные данные могут свидетельствовать о разном составе клинической и социально-психологической выраженности травматических эмоций у детей в зависимости от принадлежности испытуемых к конкретной подгруппе.

По данным «Шкалы личностной тревожности учащихся 10-16 лет» А.М. Прихожан были выявлены статистически значимые различия в уровне показателей обиды (Uэмп = 155 < Uкрит (170) (при $\mathrm{p} \leq 0,05))$ и общего индекса агрессивности $($ Uэмп = $112<$ Чкрит (362) (при $\mathrm{p} \leq 0,01)$ ); при этом уровень данных показателей у Группы-2 выше, чем у Группы-1. Подросткам, подвергшимся физическому насилию в семье, в большей мере, чем подросткам, не подвергавшимся насилию, свойственны чувство, вызванное завистью и ненавистью к окружающим, обусловленное горечью, гневом на весь мир за действительные или мнимые страдания. 
У подростков, подвергшихся фризическому насилию, отмечено наличие статистически значимых связей между критериями “Физическая агрессия» и критерием “C» (Избегание) ( $r$-Спирмена = 0,476 при $\mathrm{p} \leq 0,05)$; «Вербальная агрессия" и критерием «С» (Избегание) (r-Спирмена = 0,629 при $p \leq 0,05)$; «Вербальная агрессия» и критерием «D» (Возросшая возбудимость) (r-Спирмена = 0,525 при $\mathrm{p} \leq 0,05)$; «Вербальная агрессия» и критерием «F» (Нарушения функционирования) ( $r$-Спирмена $=0,516$ при $\mathrm{p} \leq 0,05)$; «Подозрительность» и критерием «C» (Избегание) ( $r$-Спирмена $=0,442$ при $\mathrm{p} \leq 0,05)$; “Обида» и критерием «B» (Навязчивое воспроизведение) ( $r$-Спирмена = 0,474 при $p \leq 0,05)$; «Косвенная агрессия» и критерием «С» (Избегание) (r-Спирмена = 0,536 при $p \leq 0,05)$. Другими словами, у подростков, подвергшихся физическому насилию в семье, агрессия по отношению к миру увеличивается прямо пропорционально увеличению уровня посттравматического стрессового расстройства.

В Группе-1 не выявлено статистически значимых связей между критериями посттравматического стрессового расстройства и агрессии. Можно предположить, что уровень агрессии зависит не только от степени стрессового расстройства, но, возможно, связан с объективными условиями их жизни. Продолжением данного исследования может стать дальнейшее изучение обстоятельств, связанных с агрессивностью подростков посредством анализа особенностей их интеллекта, условий жизни и учебы, связанных с их материальным обеспечением и условиями проживания, морально-психологическим климатом в ближайшем окружении, уровнем материально-технического обеспечения и организации учебного процесса и т.д.

Таким образом, предположение о том, что подросткам, пережившим такие травмирующие события как фризическое насилие в семье, свойственна повышенная агрессивность, частично доказано.

Было выявлено, что подростки, подвергшихся фризическому насилию, находятся под воздействием происшедшего с ними травмирующего события, тем менее они склонны к проявлению всех видов тревожности. Таким образом, в результате проведенного исследования предположение о том, что психическая травма, полученная ребенком в результате физического насилия в семье, приводит к изменению уровня его тревожности, частично подтверждается.

Результаты данного исследования подтверждают наличие связи между уровнем ПТСР, тревожностью и агрессивностью у подростков, подвергшихся физическому насилию в семье. Полученные данные могут стать основой для разработки программ психологической помощи подросткам, реализации комплексного мониторинга и прогнозирования эмоционального состояния ребенка, пережившего фризическое насилие в семье, а также разработке рекомендаций, направленных на улучшение психоэмоционального состояния детей, подвергшихся насилию. 


\section{Литература}

1. Бабаева Е.А. Тревожность ребенка как фактор психологического неблагополучия // Образовательная направленность процесса физического воспитания и формирования здорового образа жизни дошкольников и младших школьников: материалы межрегион. науч.-практ. конф. / Сибир. гос. ун-т физ. культуры и спорта [и др.]. - Омск. - 2013. - С. 171-173.

2. Брюкнер М. Насилие в семье: локальные действия - международная проблема // Журнал исследований социальной политики [Электронный ресурс]. - 2017.-№ 7 (2). - С. 261-272. -Режим доступа: https://jsps.hse. ru/article/view/3599/3181, свободный. - Данные соответствуют 06.11.2018.

3. Дворецкая О.В. Психологическое насилие над детьми // Социальная сеть работников образования [Электронный ресурс]: сайт в рамках проекта nsportal.ru. - Электронные данные. 2014. Режим доступа : http://nsportal.ru/shkola/raznoe/library/2014/11/10/psikhologicheskoe-nasilie-naddetmi, свободный. Данные соответствуют 23.09.2018.

4. Курзин Л.М. Синдром жестокого обращения с ребенком. Судебно-медицинские аспекты / Л.М. Курзин, А.А. Ефимов, Е.Н. Лазарева // Вестник ТГУ [Электронный ресурс] : серия: Естеств. и техн. науки. - Электронные данные. - 2014. - Т. 19. - вып. 2. - С. 753-757. - Режим доступа: https://cyberleninka.ru/article/n/sindrom-zhestokogo-obrascheniya-s-rebenkomsudebno-meditsinskie-aspekty,свободный. - Данные соответствуют 16.09.2018.

5. Николаева С. Б. Насилие над детьми в семье / С.Б. Николаева // Региональная Политика. Экономика. - 1999. - № 5. - С.79-80.

\section{EMOTIONAL SPHERE OF ADOLESCENTS WHO EXPERIENCED DOMESTIC VIOLENCE}

Razina N.V. (RSUH, Moscow, Russia) Danshina D.S. (School 2103, Moscow, Russia)

The article presents a comparative study of intensity of posttraumatic stress disorder symptoms among adolescents who experienced domestic voidance and those, who did not. In spite of the fact that intensity of post-traumatic stress disorder symptoms did not show significant difference, correlation relationship between emotional parameters of children who experienced violence and children who did not experience violence differed. It was also discovered that adolescents who experienced domestic violence express envy and hatred against people around, caused by bitterness and anger to the whole world for real or perceived suffering.

Keywords: emotional sphere, violence, posttraumatic stress disorder, aggression, anxiety. 